\title{
Client Satisfaction towards Quality of Health Services: An Assessment at Primary Healthcare of District Gujranwala
}

\author{
Kauser Aftab Khan ${ }^{1}$, Shahzad Ali Khan ${ }^{2}$, Zubia Qureshi ${ }^{3}$, Moazzam Ali Khan ${ }^{4}$, Fouzia Nadeem Gill ${ }^{5}$, \\ Mudassar Mushtaq Jawad Abbasi ${ }^{6}$ \\ ${ }^{1}$ WMO District Gujranwala, Pakistan \\ ${ }^{2}$ Department of MNCH/Health System, Health Services Islamabad, Pakistan \\ ${ }^{3}$ Apex Consulting Pakistan, Pakistan \\ ${ }^{4}$ Ghazi khan Medical College, Dera Ghazi Khan, Pakistan \\ ${ }^{5}$ Health Services Academy, Islamabad, Pakistan \\ ${ }^{6}$ Department of Epidemiology and Biostatistics Health Services Academy, Islamabad, Pakistan
}

\begin{abstract}
Article Info
Article history:

Received Sep 29, 2016

Revised Jan 22, 2017

Accepted Feb 15, 2017

Keyword:

Public Health Units

Client's Satisfaction

Health Care Services

ABSTRACT

This survey designed to evaluate the satisfaction level and the factors that affect the patient satisfaction regarding health care delivery services with the aim to improve the services in the primary health care settings of Gujranwala. A Cross Sectional Study done on randomly selected patients attending the basic health units of Gujranwala, with more than18 years of age. Pretested structured "Liker scale questionnaire" was used for data collection. Out of total respondents, $62(41.3 \%)$ clients were satisfied with the services provided by the basic health units of Gujranwala. The factors identified to determine patient satisfaction were accessibility of services, behavior of staff, health education, level of cleanliness, drug availability and miscellaneous services. Not a single ranked area of satisfaction noticed. Client's occupation and income had significant relationship with the patient satisfaction level. Gender, age, and education of clients were not contributing factors; they not affect the client satisfaction level. Less than half clients were satisfied with the services provided by the basic health units. Management of health facilities needs to improve the services.
\end{abstract}

Copyright $\odot 2017$ Institute of Advanced Engineering and Science. All rights reserved.

Corresponding Author:

Zubia Qureshi,

Assistant M\&E manager (Polio PCM Project),

Apex Consulting Pakistan.

Email: drzubiaqureshi@gmail.com

\section{INTRODUCTION}

The concept and idea of client satisfaction is not novel. Clients are the most important stakeholders in the modern world of health care industry [1]. It can be defined as the balance between the received care and his/her expectation about the care. In any health system the first and foremost goal is the patient satisfaction but it is hard to quantify the satisfaction because it has two different aspects one is the clinical and second is the non-clinical, these aspects affect the patient satisfaction level [2].

To maintain the quality of the health care system is a global issue. Previously, the quality was based only on the standard practices of the professionals but now a day; this concept has been widely accepted as a core component for improving the performance and efficiency of health care delivery system [3]. As the patients are using the services of the health care facilities, so, they are the best source of feedback of the services; they can accurately tell and give inputs that can provide great help in improving and enhancing the health care services at any level that can done through the proper ratification of the identified weak areas [4].

This study was design to measure the level of client's satisfaction and to assess the factors that affect the satisfaction level of clients regarding primary health services. It would be useful for health service 
planners to improve the OPD services, especially where the patients showed concern on the service utilization during data collection. In addition, the result of this study can used by the health providers of hospital for improvement of services and for strengthening the relationship between the patients and health care providers of the hospital.

\section{RESEARCH METHOD}

Descriptive cross sectional study was conducted in BHUs of Tehsil Wazirabad, district Gujranwala. Randomly selected 150 patients above eighteen years of age, who were receiving health care services from BHUs in the study period, were included in the study. Those who had any mental illness excluded from the study.

The main indicators of the patient's satisfaction level used in current research were accessibility of services, the humanness of staff, education/information provided by staff, drug availability, and cleanliness of basic health units (BHUs). The level of patient satisfaction was measured by using five point Likert scale questionnaire. Items for areas of satisfaction were recorded as: Very satisfied: 5, Satisfied: 4, Average: 3, Dissatisfied: 2 and Very dissatisfied: 1. the mean of every domain was computed which was divided by its number of items to find out the satisfaction or dissatisfaction factor as a cut point. In the end, overall satisfaction level was divided into two groups. The respondents securing a score of mean or more considered as satisfied while those securing less than the mean score labeled as not satisfied. While, in inferential analysis the Chi Square/ Fisher Exact Test used to find the association of various variables. The p- value less than 0.05 considered as statistically significant. Analysis done by SPSS software.

\section{RESULTS AND ANALYSIS}

\subsection{Baseline characteristics of the sample}

Among 150 participants 77 (51.3) were females while the rest 73 (48.7\%) were male respondents. Age of the clients ranges from 18 to 80 years, while the mean age was $35.53 \pm 15.66$ years. The participant's age distributed into four groups. The first group from 18 to 27 years old has the highest percentage of 55 $(36.7 \%)$ clients. The second group from 28 to 37 years old has $36(24 \%)$ clients. While the 3rd group, from 38 to 47 years old, and the 4th group, from 48 years and above has $29(19.3 \%)$ and $30(20 \%)$ clients respectively. About one fourth 38 (25.3\%) of the respondents were illiterate. Among the total $44(29.3 \%)$ had finished primary school followed by $41(27.3 \%)$ of the respondents who had ended up in secondary school. While 27 (18\%) had finished high school education level. The highest proportion of respondents was unemployed 104 (69.3). Regarding monthly income, the patients divided into four income groups. The group who won the highest proportion 42 (28\%), was able to earn 10001 to 30000/Rs per month. About 33 (22\%) were able to earn from less than or equal to 10000 Rs while three (2\%) earn more than 1000, 1 Rs per month. About half of them 72 (48\%) had no income source as shown in Table 1.

Table 1. Baseline Characteristics of The Clients

\begin{tabular}{lc}
\hline \multicolumn{1}{c}{ Variable } & $\mathrm{N}(\%)$ \\
\hline Gender & $77(51.3)$ \\
Female & $73(48.7)$ \\
Male & \\
Age groups & $55(36.7)$ \\
18-27 & $36(24)$ \\
$28-37$ & $29(19.3)$ \\
$38-47$ & $30(20)$ \\
$>48$ & \\
Occupation & $104(69.3)$ \\
Unemployed & $46(30.7)$ \\
Employed & \\
Education & $38(25.3)$ \\
Illiterate & $44(29.3)$ \\
Primary & $41(27.3)$ \\
Secondary & $27(18)$ \\
Metric and above & \\
Monthly income in PKR & $72(48)$ \\
No income & $33(22)$ \\
$001-10,000$ & $4242(28)$ \\
1000,1-30,000 & $3(2)$ \\
>30,001 &
\end{tabular}

IJPHS Vol. 6, No. 1, March 2017: $7-12$ 


\subsection{Client's satisfaction with BHUs services}

Out of 150 clients $62(41.3 \%)$ expressed satisfaction with the services rendered to them. More than half $88(58.7 \%)$ was not satisfied with the services provided by BHUs of Gujranwala.

\subsubsection{Client's Satisfaction with access to BHUs}

The average distance from home to BHU reported as $1.78 \pm 1.9 \mathrm{~km}$ and average time to reach the facility was $17.09 \pm 10.44$ minutes. The majority of clients $143(95.3 \%)$ reported living close to the health facilities within a distance of $5 \mathrm{~km}$, and $147(98 \%)$ reported that they were able to reach the facility within 30 minutes. The average waiting time at the facilities for registration was $3.26 \pm 1.92$ minutes with about $4.61 \pm$ 2.3 minutes of seeing a doctor. More than half of the client's 95 (63.3) preferred to go to a health facility by walk.

\subsubsection{Client Satisfaction with humanness/behavior of staff}

According to half participants $77(51.3 \%)$ registration staff behavior is not good with clients, while $73(48.7 \%)$ indicated that it was good. According to the majority of the client's $122(81.3 \%)$ doctors behavior towards patients is good. In case of the dispenser's $57(38 \%)$ and $93(62 \%)$ were indicated as not good and good behavior of dispensers with patients. According to $110(73 \%)$ clients, LHVs were not available in BHUs of Gujranwala. The majority of the clients were significantly not satisfied with the behavior of registration staff, doctors, LHVs, and dispensers with p-value less than 0.01. Privacy, comfort and safety during the checkup were also significantly not satisfactory domains (Table 2).

\subsubsection{Client Satisfaction about health information}

Findings showed that $68(45.3 \%$ ) of registration staff had good communication skills. Regarding information and assistance, provision of registrar staff $63(42 \%)$ mentioned that it is good. According to $108(72 \%)$ and $84(56 \%)$ information provided by doctors and registration staff are ranked as good. The results of the test between health information, provision of staff and patient satisfaction level showed that each component had significant relationship with the patient satisfaction level with p-value <0.001 (Table 2).

\subsubsection{Client Satisfaction about drugs/medicines}

Among clients $94(63 \%)$ were satisfied with the availability of drugs while about $1 \%$ had poor experience regarding medicines availability. According to the $78(52 \%)$ of the clients medicines available were not of good quality. The results of the test between drug/medicines components and patient satisfaction level showed that there was no significant relationship of availability, quality and cost of drugs with the patient satisfaction level. A significant relationship found between cleanliness of BHUs and toilet facility with the patient satisfaction level (Table 2).

\subsubsection{Client Satisfaction about miscellaneous services}

Results indicate that the majority of the LHVs seats are vacant in the study area. The majority of the clients replied that drinking water provided by BHUs is not of good quality. Only $47(31.3 \%)$ mentioned that furniture in hospitals is good. The results between the care provided by LHV, drinking water quality, furniture condition, and overall quality of health services showed that these had significant relationship with the patient satisfaction level, while turn to a doctor for a checkup is not significantly associated with patient satisfaction level (Table 2). 
Table 2. Client's Satisfaction with PHC Services

\begin{tabular}{|c|c|c|c|c|}
\hline \multicolumn{2}{|l|}{ Variables } & Satisfied N (\%) & Not satisfied N (\%) & p-value* \\
\hline \multicolumn{5}{|c|}{ Client's satisfaction with humanness/behavior of staff } \\
\hline \multirow{2}{*}{ Registration staff behavior $\&$ attitude } & Good & $54(36)$ & $19(12.7)$ & \multirow{11}{*}{$<0.01$} \\
\hline & Not good & $8(5.3)$ & $69(46)$ & \\
\hline \multirow{2}{*}{ Doctor behavior and attitude } & Good & $61(40.7)$ & $61(40.7)$ & \\
\hline & Not good & $1(0.7)$ & $27(18)$ & \\
\hline \multirow{3}{*}{ LHV behavior and attitude } & Good & $19(12.7)$ & 0 & \\
\hline & Not good & $10(6.7)$ & $11(7.3)$ & \\
\hline & Not available & $33(22)$ & $77(51.3)$ & \\
\hline \multirow{2}{*}{ Dispenser behavior and attitude } & Good & $52(34.7)$ & $41(27.3)$ & \\
\hline & Not good & $10(6.7)$ & $47(31.3)$ & \\
\hline \multirow{2}{*}{ Privacy, comfort and safety } & Good & $57(38)$ & $11(7.3)$ & \\
\hline & Not good & $5(3.3)$ & $77(51.3)$ & \\
\hline \multicolumn{5}{|c|}{ Client satisfaction about health information by staff } \\
\hline \multirow{2}{*}{ Communication skills of staff } & Good & $50(33.3)$ & $18(12)$ & \multirow{8}{*}{$<0.01$} \\
\hline & Not good & $12(8)$ & $70(46.7)$ & \\
\hline \multirow{2}{*}{ Registration staff Provide information } & Good & $46(30.7)$ & $17(11.3)$ & \\
\hline & Not good & $16(10.7)$ & $71(47.3)$ & \\
\hline \multirow{2}{*}{$\begin{array}{l}\text { Doctor provides information } \\
\text { understandable language }\end{array}$} & Good & $61(40.7)$ & $47(31.3)$ & \\
\hline & Not good & $1(0.7)$ & $41(27.3)$ & \\
\hline \multirow{2}{*}{$\begin{array}{l}\text { Dispenser provides information about } \\
\text { medicine }\end{array}$} & Good & $50(33.3)$ & $34(22.7)$ & \\
\hline & Not good & $12(8)$ & $54(36)$ & \\
\hline \multicolumn{5}{|c|}{ Client satisfaction about cleanliness of health service } \\
\hline \multirow{2}{*}{ Cleanliness of BHUs } & Yes & $52(34.7)$ & $8(5.3)$ & \multirow{4}{*}{$<0.01$} \\
\hline & No & $10(6.7)$ & $80(53.3)$ & \\
\hline \multirow{2}{*}{ Cleanliness of toilets } & Yes & $51(34)$ & $12(8)$ & \\
\hline & No & $11(7.3)$ & $76(50.7)$ & \\
\hline \multicolumn{5}{|l|}{ Client satisfaction about miscellaneous services } \\
\hline \multirow{3}{*}{ Care provided by LHV } & Good & $18(12)$ & $1(0.7)$ & \multirow{3}{*}{$<0.01$} \\
\hline & Not good & $11(7.3)$ & $10(6.7)$ & \\
\hline & Not available & $33(22)$ & $77(51.3)$ & \\
\hline \multirow{3}{*}{ Turn of checkup by doctor } & Quick & $38(25.3)$ & $62(41.3)$ & \multirow{3}{*}{0.07} \\
\hline & Slightly delayed & $23(15.3)$ & $20(13.3)$ & \\
\hline & Delayed & $1(0.7)$ & $6(4)$ & \\
\hline \multirow{2}{*}{ Quality of drinking water } & Good & $36(24)$ & $5(3.3)$ & \multirow{6}{*}{$<0.01$} \\
\hline & Not good & $26(17.3)$ & $83(55.3)$ & \\
\hline \multirow{2}{*}{ Condition of furniture } & Good & $39(26)$ & $8(5.3)$ & \\
\hline & Not good & $23(15.3)$ & $80(53.3)$ & \\
\hline \multirow{2}{*}{ Overall quality of all services } & Good & $50(33.3)$ & $5(3.3)$ & \\
\hline & Not good & $12(8)$ & $83(55.3)$ & \\
\hline
\end{tabular}

\subsubsection{Overall client's satisfaction with ranked health services}

When items of Likert scale for areas of satisfaction recoded, the mean and standard deviation for the humanness of staff was $1.56(\mathrm{SD}=0.49)$, provision of health education was $1.53(\mathrm{SD}=0.05)$, drug availability was $1.40(\mathrm{SD}=0.49)$, comprehensiveness of services was $1.155(\mathrm{SD}=0.49)$, and for the effectiveness of services was $1.54(\mathrm{SD}=0.77)$. After dividing these scores by the number of items in each area, not a single ranked area of satisfaction noticed as shown in Table 3.

Table 3. Overall Client Satisfaction with Ranked Health Services

\begin{tabular}{lccccc}
\hline Domain & $\begin{array}{c}\text { No. of } \\
\text { items }\end{array}$ & Male N (\%) & Female N (\%) & Total N (\%) & $\begin{array}{c}\text { Total Mean/ } \\
\text { Number }\end{array}$ \\
\hline Humanness of staff & 5 & $1.63(0.48)$ & $1.50(0.50)$ & $1.56(0.49)$ & 0.312 \\
Health education & 4 & $1.52(0.50)$ & $1.54(0.50)$ & $1.53(0.50)$ & 0.382 \\
Drugs availability & 2 & $1.45(0.50)$ & $1.36(0.48)$ & $1.40(0.49)$ & 0.7 \\
Cleanliness & 2 & $1.57(0.49)$ & $1.50(0.50)$ & $1.54(0.50)$ & 0.77 \\
Miscellaneous & 5 & $1.67(0.47)$ & $1.44(0.49)$ & $1.55(0.49)$ & 0.31 \\
\hline
\end{tabular}

\subsection{Client's baseline characteristics and satisfaction with health services}

The results between client's sociodemographic and satisfaction with BHUs health services showed that client's occupation and income had significant relationship with the patient satisfaction level. Gender, age, and education of clients were not contributing factors ant not affect the satisfaction level of the clients.

IJPHS Vol. 6, No. 1, March 2017 : 7 - 12 


\section{DISCUSSION}

To provide services in health care according to the felt needs of the patients and clients is most important to improve the service delivery of the health care system. There is no use of adding values to the service until it will not be according to the patient's demands.

Present study done to assess the client's satisfaction level in BHUs of Gujranwala. According to the results, less than half $(41.3 \%)$ clients were satisfied with the services provided by the BHUs. In other study conducted in PIMS Islamabad, Pakistan the satisfaction, level of clients is slightly high (54\%) than the results of this study [5]. The results of clients satisfaction level contrast with the studies of India, Thailand, Cambodia according to which level of client satisfaction with the health services rendered at the health facility was 77\%, 86.7\%, 98.5\% [6]-[9]. Other studies of Thailand and India revealed that the most of clients $71 \%$ and $98 \%$ reported a high level of satisfaction [10],[11].

The behavior of the health care providers influences a lot towards getting the patient satisfaction. A research study reported that the most influential predictor for patient satisfaction with the public services was the provider's behavior and politeness especially respect [12] Clients of this study were not satisfied with the behavior of registration staff, doctors, LHVs, and dispensers. Privacy, comfort and safety during checkup were also not satisfactory. Same results found in the study of Cambodia, majority of the respondents were less satisfied with registration service [9].

There are some findings that physicians and nurses' communication skills with Patients are the key components to a high level of patients' satisfaction. In a study in Ireland it is mentioned that good interaction between physicians and their patients is the milestone to reach clients' satisfaction and continuous improvement of quality of care"[13]. In this study, the results regarding health education provision by staff and patient satisfaction level showed that majority of the clients were not satisfied with the communication skills and education or information given by the health care staff.

The majority of the clients interviewed agreed that they obtained all the drugs that prescribed for them. However, some disagreed and claimed to purchase from outside the hospital. Availability of essential drugs is an important factor influencing patients' level of satisfaction observed in several studies in different settings [7],[14]-[16].

In this study the ranked areas for assessing the clients level of satisfaction was accessibility of services, behavior of staff, health education, cleanliness, and drug availability. "Not a single ranked area of satisfaction was noticed. Tanzania, patients' also showed overall dissatisfaction with the quality of care. The ranked areas in this study were assurance, reliability, tangible, empathy, and responsiveness [17]. According to Indian study, the main factors noticed to affecting the utilization of primary health care services were easy accessibility, low cost, less waiting time, and presence of cooperative staff [11].

\section{CONCLUSION OF THE STUDY}

It concluded that $41.3 \%$ of the clients were satisfied with the services provided by the BHUs. The factors identified to determine patient satisfaction were accessibility of services, behavior of staff, health education, level of cleanliness, drug availability and miscellaneous services. Not a single ranked area of satisfaction noticed. Client's occupation and income had significant relationship with the patient satisfaction level. Gender, age, and education of clients were not contributing factors; they not affect the satisfaction level of the clients. It recommended that Hospital management should focus on the quality, responsiveness of services. There should be a focus on improving the communication skills of staff in terms of compassion, politeness and active listening by tannings. In addition, the hospital management should focus on the cleanliness of the health facility.

\section{ACKNOWLEDGEMENT}

The authors would like to sincerely thank data collectors and study participants who ever contributed for this work.

\section{REFERENCES}

[1] De Silva A. and Valentine N., "A framework for measuring responsiveness," World Health Organization, Geneva, 2000 .

[2] Agarwal D., "Health sector reforms: Relevance in India," Indian Journal of Community Medicine, vol/issue: 31(4), pp. 220, 2006.

[3] Woodring S., et al., "Development and testing of patient satisfaction measure for inpatient psychiatry care," Journal of Nursing Care Quality, vol/issue: 19(2), pp. 137-48, 2004. 
[4] Baba I., "Experiences in quality assurance at bawku hospital eye department, Ghana," Community Eye Health, vol/issue: 17(50), pp. 31, 2004

[5] Anjum J., "Patient Satisfaction towards Out Patient Department Services in Pakistan Institute of Medical Sciences," Islamabad, Mahidol University, 2005.

[6] Kuzma J., et al., "Assessment of patients' satisfaction with rural health services," 2012.

[7] Assefa F. and Mosse A., "Assessment of Clients' satisfaction with health service deliveries at jimma university specialized hospital," Ethiopian journal of health sciences, vol/issue: 21(2), pp. 101-10, 2011.

[8] Mandokhail A. K., "Patient satisfaction towards Outpatient Department (OPD) Services of medicine in Banphaeo Autonomous Hospital Samut Sakhon Province," Thailand, Mahidol University, 2007.

[9] Vadhana M., "Assessment of patient satisfaction in an outpatient department of an autonomous hospital in Phnom Penh," Cambodia, Ritsumeikan Asia Pacific University, 2012.

[10] Upreti S., "Consumer Satisfaction towards Health centers in Suphanburi province, Thailand," MPHM Thesis in Primary Health Care Management, Bankok, Faculty of Graduate studies, Mahidol University, 1994.

[11] Rasheed N., et al., "Client Satisfaction and Perceptions about Quality of Health Care at a Primary Health Centre of Delhi, India," Indian Journal of Community Health, vol/issue: 24(3), pp. 237-42, 2012.

[12] Shreshta A., et al., "Patient satisfaction at rural outreach dental camps-a one year report," The International Electronic Journal of Rural and Remote Health Research, Education. Practice and Policy, pp. 1-6, 2008.

[13] Likun P., "Strategic issues for reducing patient waiting time and improving satisfaction with services at outpatient department of first affiliated," Kunming Medical college, PRCA, MS Thesis in Health Development Program, Bangkok, Faculty of Graduate Studies, Chulalongkorn University, 1996.

[14] Jackson J. L., et al., "Predictors of patient satisfaction," Social science \& medicine, vol/issue: 52(4), pp. 609-20, 2001.

[15] Leshabari M. T., et al., "Motivation of health care workers in Tanzania: a case study of Muhimbili National Hospital," 2008.

[16] Quintana J. M., et al., "Predictors of patient satisfaction with hospital health care. BMC health services research," vol/issue: 6(1), pp. 102, 2006.

[17] Khamis K. and Njau B., "Patients' level of satisfaction on quality of health care at Mwananyamala hospital in Dar es Salaam, Tanzania," BMC health services research, vol/issue: 14(1), pp. 400, 2014. 